\title{
Distress about mating rivals
}

\author{
DAVID M. BUSS,$a$ TODD K. SHACKELFORD ${ }^{b}$ JAE CHOE ${ }^{c}$ \\ BRAM P. BUUNK, ${ }^{d}$ AND PIETERNEL DIJKSTRA ${ }^{d}$ \\ ${ }^{a}$ University of Texas; ${ }^{b}$ Florida Atlantic University; ${ }^{c}$ Seoul National University, Korea; \\ and ${ }^{d}$ University of Groningen, The Netherlands
}

\begin{abstract}
This research tested the evolutionary psychological hypothesis that men and women would be most distressed about threats from rivals who surpass them on sex-linked components of mate value. Six predictions were tested in samples from three cultures, the United States $(N=208)$, the Netherlands $(N=349)$, and Korea $(N=174)$. Five predictions were supported in all three cultures. Korean, Dutch, and American men, more than corresponding women, report greater distress when a rival surpasses them on financial prospects, job prospects, and physical strength. Korean, Dutch, and American women, in contrast, report greater distress when a rival surpasses them on facial and bodily attractiveness. The cultures differed on some variables. Korean women and men, for example, differed from Americans and Dutch in reporting more distress over rivals who had better financial prospects, better job prospects, and higher status and prestige. Americans exceeded Koreans in reporting distress when rivals had more attractive faces and bodies, whereas the Dutch exceeded the other cultures in reporting more distress when rivals had a better sense of humor. Discussion focuses on possible proximate psychological mechanisms underlying distress over rivals and the theoretical importance of intrasexual competition.
\end{abstract}

Successful mating, from an evolutionary perspective, poses many adaptive problems. The first is initial mate selection, and this adaptive problem has received the most research attention in the mating field (Buss, 1989; Buss \& Schmitt, 1993; Feingold, 1992; Gangestad, 1993; Graziano, Jensen-Campbell, Shebilske, \& Lundgren, 1993; Kenrick \& Keefe, 1992; Simpson \& Gangestad, 1992; Thornhill \& Gangestad, 1993; Townsend, 1995). A second problem, temporally following mate choice, is successful attraction, and this too has received some research attention (Buss, 1988; Schmitt \& Buss, 1996; Tooke \& Camire, 1991). A third adaptive problem just beginning to be studied is retention of a long-term mate (Buss, 2000; Buss \& Shackelford, 1997). The success of

Correspondence should be addressed to David $\mathbf{M}$. Buss, Department of Psychology, University of Texas, Austin, TX 78712, or via the Internet: dbuss@psy. utexas.edu. solving the retention problem, at the broadest level, involves two related tasks-grappling with a partner who may be tempted to defect and fending off interested rivals who may attempt to lure one's partner.

From the perspective of evolutionary psychology, adaptive problems that recur over time tend to select for specific psychological mechanisms possessing design features that solve those problems. The recurrent problem of mate selection, for example, appears to have forged universal human preferences for fertile and resourceful mates (Buss, 1994; Kenrick \& Keefe, 1992; Symons, 1979). The recurrent problem of non-reciprocators in social exchange, to take another example, appears to have fashioned psychological mechanisms of cheater detection (Cosmides, 1989). It is reasonable to expect that interested rivals vying for an already mated individual also would have been a recurrent adaptive problem. An evolutionary psychological analysis, therefore, anticipates specific psychological mecha- 
nisms triggered by the adaptive threat posed by interested rivals.

The presence of an intrasexual competitor who might attempt to lure a mate away from an existing long-term mateship, by itself, may not constitute an adaptive threat. When an interested rival is more desirable according to the preferences of one's partner, however, the adaptive threat become most relevant, and the anticipated evolved psychological mechanisms are activated. Operationalizing mate value or overall desirability, however, has proven to be sufficiently complex that no one has yet developed a comprehensive measure of it. Still, much is known about the components of mate value, especially those that are sexlinked.

Men's mate value, more than women's, is linked with the ability to secure resources, as well as the qualities that tend to lead to resources such as ambition, industriousness, and older age. Women universally desire men with good financial prospects, and this preference does not diminish when women gain personal access to financial resources, nor when women achieve high socioeconomic status, nor even when women reside in cultures of relatively high economic parity between the sexes (Buss, 1989, 1994; Townsend, 1987; Wiederman \& Allgeier, 1992). Furthermore, because protection has been a recurrent adaptive problem that women face, including aggression at the hands of men, women place a greater premium on qualities that signal a man's ability to protect her, such as physical strength and athletic prowess (Buss, 1994; Ellis, 1992). The ability to secure economic resources and athletic prowess are more central to men's than to women's mate value.

Women's mate value, in contrast, is more influenced by signals of fertility, such as youth, physical attractiveness, and a low waist-to-hip ratio (Buss, 1989; Kenrick \& Keefe, 1992; Singh, 1993). In a study of 37 cultures (Buss, 1989), men universally placed a greater premium than did women on youth and physical attractiveness, and laboratory experiments have replicated this sex difference (Kenrick, Neuberg, Zierk, \&
Krones, 1994). Physical attractiveness is more central to women's than to men's mate value.

A clear hypothesis about psychological sensitivity to specific rivals may be derived from this evolutionary analysis: Men and women should be most distressed about threats from rivals who exceed them on the relevant sex-linked components of mate value. Six specific sex-linked predictions may be derived from this hypothesis: Men will be more distressed by interested rivals who, relative to themselves, have better financial prospects (Prediction 1), better future job prospects (Prediction 2), higher status and prestige (Prediction 3), and greater physical strength (Prediction 4). Women will be more distressed by interested rivals who, relative to themselves, have a more attractive face (Prediction 5) and a more attractive body (Prediction 6).

All psychological theories, even the most ardently anti-nativist ones such as Skinnerian learning theory, contain assumptions, often implicit, about universal evolved psychological mechanisms (Symons, 1987). Evolutionary psychological theories differ from most mainstream theories in proposing that these universal mechanisms are likely to be domain-specific in nature, tailored to the recurrent adaptive problems our species has confronted over thousands or millions or years. Although evolutionary psychologists predict that manifest behavior will be highly variable and sensitive to context (DeKay \& Buss, 1992), the underlying domain-specific psychological mechanisms are proposed to be universal, and so should be found in diverse cultures. Thus, the current studies on rivalry include three cultures differing widely on dimensions such as individualism and collectivism (Markus \& $\mathrm{Ki}$ tayama, 1991; Triandis, 1995)-Korea, the Netherlands, and the United States.

\section{Method}

\section{Participants}

American participants. American participants were 106 women and 102 men. They 
ranged in age from 17 to 22 years, with a mean age of 18.5 years ( $S D=0.82$ years). Participants were students in a psychology class at a large state university and received course credit for participating in this study.

Korean participants. Korean participants were 83 women and 91 men who were students at a large university in Seoul. Participants ranged in age from 18 to 37 years, with a mean age of 22.9 years $(S D=3.26$ years).

Dutch participants. Dutch participants were 162 males and 182 females, all of whom were students at the University of Groningen in the Netherlands. Participants ranged in age from 18 to 31 years, with a mean of 22.1 years $(S D=2.34$ years $)$.

\section{Materials and procedure}

Participants completed an instrument containing background information, and they then rank-ordered 11 rival characteristics on how upsetting these characteristics were, from most upsetting to least upsetting. In addition to six probes designed to test each of the six specific predictions, five filler items were interspersed among the set. Participants received the following instructional set:

Please think of a serious or committed romantic relationship that you have had in the past, that you currently have, or that you would like to have. Imagine that you discover that the person with whom you've been seriously involved became seriously interested in a long-term relationship with someone else. What would upset or distress you more? Please rank-order the following items on the degree to which they would upset you. Give a "1" to the most upsetting, a " 2 " to the second most upsetting, a " 3 " to the third most upsetting . . . all the way down to " 11 " for the least upsetting.

Participants were then presented with a sentence stem and the 11 probes:

You found out that the person that your partner became interested in:
1. was more kind and understanding than you

2. had a more attractive face than you

3. was a more skilled sexual partner than you

4. was higher in status and prestige than you

5. was more willing to commit to a longterm relationship than you

6. had better financial prospects than you

7. had a more attractive body than you

8. was a virgin (had no previous sexual experience)

9. was physically stronger than you

10. had better future job prospects than you

11. had a better sense of humor than you

The English version was translated into Korean and Dutch separately, back-translated from Korean and Dutch to English by other bilingual speakers, and then translation discrepancies resolved by additional bilingual speakers.

\section{Results}

Analyses were conducted to test the six specific predictions, separately for each culture. In addition, one-way analyses of variance (ANOVAs) were computed to examine cultural differences, with culture as the independent variable. Finally, effect sizes, as indexed by the $d$-statistic (Cohen, 1988), were computed for all effects.

\section{Sex differences in distress about rivals in the American sample}

Table 1 shows the results for the American sample-means, standard deviations, $t$-tests, $p$-values, and $d$-statistics. Predictions 1 and 2 were strongly confirmed. Men were significantly more distressed than were women when the rival had better financial prospects and better future job prospects than they did, with magnitude of effects ranging from one-third to one-half standard deviation $(S D)$. Prediction 3 , involving a rival's greater status and prestige, was not supported; no significant sex differences emerged. Predic- 
Table 1. Sex differences in upset as a function of rival characteristic: American sample

\begin{tabular}{|c|c|c|c|c|c|c|c|}
\hline \multirow[b]{2}{*}{ Rival Characteristic ${ }^{\mathrm{a}}$} & \multicolumn{2}{|c|}{ Women } & \multicolumn{2}{|c|}{ Men } & \multirow[b]{2}{*}{$t$} & \multirow[b]{2}{*}{$p$} & \multirow[b]{2}{*}{$d$} \\
\hline & Mean & $S D$ & Mean & $S D$ & & & \\
\hline 1. Kind and understanding (1) & 3.18 & 2.96 & 4.69 & 3.92 & 3.14 & .002 & 0.44 \\
\hline 2. Attractive body (4) & 3.43 & 1.85 & 4.96 & 2.46 & 5.07 & .000 & 0.71 \\
\hline 3. Attractive face (3) & 3.59 & 1.99 & 4.88 & 2.85 & 3.82 & .000 & 0.54 \\
\hline 4. Sexually skilled (2) & 5.12 & 3.02 & 4.73 & 3.10 & -0.94 & .350 & 0.13 \\
\hline 5. Sense of humor (5) & 5.39 & 2.58 & 5.51 & 2.95 & 0.32 & .749 & 0.04 \\
\hline 6. Willingness to commit (9) & 6.16 & 3.13 & 6.64 & 3.21 & 1.08 & .279 & 0.15 \\
\hline 7. Status and prestige (6) & 6.37 & 2.47 & 6.16 & 3.08 & -0.55 & .585 & 0.08 \\
\hline 8. Job prospects $(10)$ & 7.58 & 1.85 & 6.77 & 2.47 & -2.69 & .008 & 0.38 \\
\hline 9. Financial prospects (7) & 7.64 & 2.30 & 6.28 & 2.80 & -3.83 & .000 & 0.53 \\
\hline 10. Virgin (11) & 8.18 & 2.72 & 8.93 & 2.43 & 2.10 & .037 & 0.29 \\
\hline 11. Physically strong (8) & 9.37 & 1.95 & 6.46 & 2.78 & -8.76 & .000 & 1.23 \\
\hline
\end{tabular}

Note: Analyses based on data provided by 106 women and 102 men. The $d f$ for all $t$-tests is $206 ; p$-values are two-tailed. The $d$ is an effect size index representing the difference between means in standard deviation units. Cohen (1988) defines effect sizes as small if they are .20 , medium if they are. 50 , and large if they are .80 or greater.

${ }^{a}$ Rival characteristics are presented from most (1) to least (11) upsetting, as reported by women. The number in parentheses following each characteristic is the corresponding upset ranking of that characteristic, as reported by men.

tion 4 was strongly supported, showing that men were more distressed than were women when the rival was physically stronger, with a $d$ greater than $1 S D$.

Predictions 5 and 6 were also strongly supported. Women reported more distress when a rival had a more attractive face and a more attractive body than they did. The magnitudes of these sex differences were in the moderate to large range, showing $d s$ of .54 and .71 , respectively. Two sex differences emerged that were not predicted in advance. American women indicated greater distress than did American men when a rival was kinder and more understanding $(d=.44)$ and when a rival was a virgin $(d=.29)$.

\section{Sex differences in distress about rivals in} the Korean sample

Analogous statistics were computed for the Korean sample, as shown in Table 2. Predictions 1 and 2 were supported, with men showing greater distress when a rival had better financial prospects and better future job prospects, with magnitude of effects ranging from small $(d=.30)$ to moderate $(d$ $=.45$ ), respectively. Prediction 3 , like the American sample, was not supported in the
Korean sample. Korean men and women did not differ in the distress they reported about a rival with superior status and prestige. Prediction 4, like the American sample, was strongly supported, with Korean men more than Korean women indicating greater upset when a rival was physically stronger $(d$ $=.66$ ).

Predictions 5 and 6 corroborated the American results, showing that Korean women were more distressed than were Korean men when a rival had a more attractive face and a more attractive body. These effects were moderate in magnitude, showing $d s$ of .40 and .46 , respectively. Unlike the American sample, no sex differences other than those predicted emerged in the analyses.

\section{Sex differences in distress about rivals in the Dutch sample}

Analogous statistics were computed for the Dutch sample, as shown in Table 3. Predictions 1 and 2 were supported, with men showing greater distress when a rival had better financial prospects and better future job prospects, with magnitude of effects ranging from large $(d=.69)$ to small $(d=$ 
Table 2. Sex differences in upset as a function of rival characteristic: Korean sample

\begin{tabular}{|c|c|c|c|c|c|c|c|}
\hline \multirow[b]{2}{*}{ Rival Characteristic ${ }^{a}$} & \multicolumn{2}{|c|}{ Women } & \multicolumn{2}{|c|}{ Men } & \multirow[b]{2}{*}{$t$} & \multirow[b]{2}{*}{$p$} & \multirow[b]{2}{*}{$d$} \\
\hline & Mean & $S D$ & Mean & $S D$ & & & \\
\hline 1. Kind and understanding (2) & 3.84 & 3.07 & 4.63 & 3.50 & 1.56 & .120 & 0.24 \\
\hline 2. Attractive face (5) & 4.27 & 2.61 & 5.36 & 2.83 & 2.65 & .009 & 0.40 \\
\hline 3. Willingness to commit (6) & 4.48 & 3.58 & 5.90 & 3.61 & 2.65 & .009 & 0.40 \\
\hline 4. Status and prestige (1) & 4.59 & 2.56 & 4.11 & 2.67 & -1.21 & .228 & 0.18 \\
\hline 5. Attractive body (9) & 5.40 & 2.80 & 6.62 & 2.47 & 3.05 & .003 & 0.46 \\
\hline 6. Job prospects (4) & 6.15 & 2.44 & 5.36 & 2.71 & -1.99 & .048 & 0.30 \\
\hline 7. Financial prospects (3) & 6.42 & 2.24 & 5.32 & 2.62 & -2.97 & .003 & 0.45 \\
\hline 8. Sense of humor (7) & 6.54 & 2.61 & 6.20 & 2.93 & -0.81 & .417 & 0.12 \\
\hline 9. Sexual skill (10) & 7.11 & 3.08 & 6.84 & 3.24 & -0.57 & .570 & 0.09 \\
\hline 10. Physically strong (8) & 8.29 & 2.30 & 6.60 & 2.79 & -4.32 & .000 & 0.66 \\
\hline 11. Virgin (11) & 8.94 & 2.65 & 9.07 & 2.39 & 0.33 & .741 & 0.05 \\
\hline
\end{tabular}

Note: Analyses based on data provided by 83 women and 91 men. The $d f$ for all $t$-tests is $172 ; p$-values are twotailed. The $d$ is an effect size index representing the difference between means in standard deviation units. Cohen (1988) defines effect sizes as small if they are .20 , medium if they are .50 , and large if they are .80 or greater.

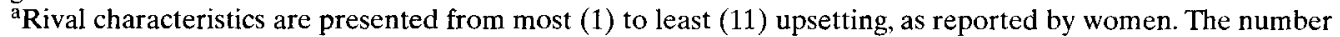
in parentheses following each characteristic is the corresponding upset ranking of that characteristic, as reported by men.

.27), respectively. Prediction 3 was supported in the Dutch sample, unlike the American and Korean samples. Dutch men, compared with Dutch women, reported that they would experience greater distress about a rival with superior status and pres- tige. Prediction 4, as in the American and Korean samples, was supported in the Dutch sample, with men more than women indicating greater upset when a rival was physically stronger $(d=.32)$.

Predictions 5 and 6 corroborated the

Table 3. Sex differences in upset as a function of rival characteristic: Dutch sample

\begin{tabular}{|c|c|c|c|c|c|c|c|}
\hline \multirow[b]{2}{*}{ Rival Characteristics ${ }^{a}$} & \multicolumn{2}{|c|}{ Women } & \multicolumn{2}{|c|}{ Men } & \multirow[b]{2}{*}{$t$} & \multirow[b]{2}{*}{$p$} & \multirow[b]{2}{*}{$d$} \\
\hline & Mean & $S D$ & Mean & $S D$ & & & \\
\hline 1. Kind and understanding (1) & 2.33 & 2.11 & 3.41 & 3.11 & 3.84 & $<.001$ & 0.41 \\
\hline 2. Attractive body (5) & 3.59 & 2.00 & 5.69 & 2.11 & 9.56 & $<.001$ & $1.02 \mathrm{r} \cdot \mathrm{r} \cdot \mathrm{r} \mathrm{r} \cdot \mathrm{c}$ \\
\hline 3. Attractive face (4) & 3.83 & 2.06 & 5.54 & 2.24 & 7.45 & $<.001$ & 0.80 \\
\hline 4. Sexually skilled (2) & 4.21 & 2.23 & 4.37 & 2.64 & 0.60 & .549 & 0.07 \\
\hline 5. Sense of humor (3) & 4.55 & 2.38 & 4.86 & 3.24 & 1.00 & .320 & 0.13 \\
\hline 6. Status and prestige (6) & 6.97 & 2.25 & 5.88 & 3.04 & -3.82 & $<.001$ & 0.41 \\
\hline 7. Willingness to commit (8) & 7.05 & 2.75 & 6.71 & 3.28 & -1.01 & .282 & 0.12 \\
\hline 8. Job prospects (7) & 7.12 & 2.10 & 6.47 & 2.79 & -2.48 & .013 & 0.27 \\
\hline 9. Physically strong (10) & 8.29 & 2.36 & 7.49 & 2.68 & -2.99 & .003 & 0.32 \\
\hline 10. Financial prospects (9) & 8.32 & 1.81 & 6.73 & 2.81 & -6.34 & $<.001$ & 0.69 \\
\hline 11. Virgin (11) & 9.73 & 1.99 & 8.86 & 2.89 & -3.29 & .001 & 0.36 \\
\hline
\end{tabular}

Note: Analyses based on data provided by 182 women and 162 men. The $d f$ for all $t$-tests is $347 ; p$-values are two-tailed. The $d$ is an effect size index representing the difference between means in standard deviation units. Cohen (1988) defines effect sizes as small if they are .20 , medium if they are .50 , and large if they are .80 or greater.

aival characteristics are presented from most (1) to least (11) upsetting, as reported by women. The number in parentheses following each characteristic is the corresponding upset ranking of that characteristic, as reported by men. 
American and Korean results, showing that Dutch women were more distressed than were Korean men when a rival had a more attractive face and a more attractive body. These effects were large in magnitude, showing $d \mathrm{~s}$ of .80 and 1.02 , respectively. Two sex differences emerged that were not predicted in advance. Like the American sample, Dutch women indicated greater distress than did Dutch men when a rival was kinder and more understanding $(d=.41)$. However, unlike the American sample, Dutch men indicated more distress than did Dutch women when a rival was a virgin ( $d$ $=.36$ ), although this finding must be qualified by the fact that virginal status of a rival was the least distressing to both sexes among all 11 rival characteristics.

\section{Sexual similarities}

Despite the consistent sex differences, the sexes within each culture showed much similarity in the rank-ordering of distressing rival qualities. Spearman rank-order corre- lations were computed between the ranks of the sexes within each culture, yielding values of .90 for the Dutch sample, .84 for the American sample, and .70 for the Korean sample. These findings reveal strong overall sexual similarity in the rank orders, but they also reveal an intriguing cultural difference. The Koreans appear to show the least similarity between the sexes, whereas the Dutch appear to show the most similarity between the sexes. We know of no theory or explanatory framework that has predicted, or would have predicted, these cultural differences in degree of sexual similarity. Future research might follow up on this intriguing finding to examine whether the cultural differences in sexual dimorphism are general across other psychological or morphological characteristics.

\section{Cultural differences in distress as a function of rival characteristics}

No predictions were advanced about cultural differences. Nonetheless, a number of

Table 4. Country differences in upset as a function of rival characteristic

\begin{tabular}{|c|c|c|c|c|c|c|c|c|}
\hline \multirow[b]{2}{*}{ Rival Characteristic ${ }^{a, b}$} & \multicolumn{2}{|c|}{ U.S. } & \multicolumn{2}{|c|}{ Korea } & \multicolumn{2}{|c|}{ Netherlands } & \multirow[b]{2}{*}{$F$} & \multirow[b]{2}{*}{$R^{2}$} \\
\hline & Mean & $S D$ & Mean & $S D$ & Mean & $S D$ & & \\
\hline Kind and understanding & $3.92_{\mathrm{c}}$ & 3.54 & $4.25_{\mathrm{c}}$ & 3.32 & $2.85_{d}$ & 2.69 & $14.72 * * *$ & .04 \\
\hline Attractive face & $4.22_{\mathrm{c}}$ & 2.53 & $4.84_{\mathrm{d}}$ & 2.77 & $4.65_{c, d}$ & 2.31 & $3.24 *$ & .01 \\
\hline Sexually skilled & $4.93_{\mathrm{c}}$ & 3.05 & $6.97_{d}$ & 3.16 & $4.28_{\mathrm{e}}$ & 2.43 & $53.74 * * *$ & .13 \\
\hline Status and prestige & $6.26_{\mathrm{c}}$ & 2.78 & $4.34_{d}$ & 2.62 & $6.45_{\mathrm{c}}$ & 2.71 & $37.91 * * *$ & .09 \\
\hline Willingness to commit & $6.39_{\mathrm{c}}$ & 3.17 & $5.21_{d}$ & 3.66 & $6.89_{\mathrm{c}}$ & 3.02 & $15.71 * * *$ & .04 \\
\hline Financial prospects & $6.98_{\mathrm{c}}$ & 2.64 & $5.84_{\mathrm{d}}$ & 2.50 & $7.56_{\mathrm{e}}$ & 2.47 & $26.77 * * *$ & .07 \\
\hline Attractive body & $4.18_{\mathrm{c}}$ & 2.30 & $6.03_{d}$ & 2.70 & $4.59_{c}$ & 2.30 & $31.17 * * *$ & .08 \\
\hline Virgin & $8.55_{c}$ & 2.60 & $9.01_{\mathrm{c}, \mathrm{d}}$ & 2.51 & $9.32_{\mathrm{d}}$ & 2.50 & $6.00 * *$ & .02 \\
\hline Physically strong & $7.94_{c}$ & 2.80 & $7.41_{c}$ & 2.70 & $7.91_{\mathrm{c}}$ & 2.54 & 2.47 & .01 \\
\hline Job prospects & $7.18_{c}$ & 2.21 & $5.74_{\mathrm{d}}$ & 2.61 & $6.81_{c}$ & 2.47 & $17.89 * * * *$ & .05 \\
\hline Sense of humor & $5.45_{\mathrm{c}}$ & 2.76 & $6.36_{\mathrm{d}}$ & 2.78 & $4.70_{\mathrm{e}}$ & 2.82 & $20.91 * * *$ & .05 \\
\hline
\end{tabular}

Note: Analyses based on data provided by 731 participants ( 208 from the United States, 174 from Korea, and 349 from The Netherlands). The $F$-values provided by one-way ANOVA, with country as the independent variable. For all $F$-values, $d f_{\text {between }}=2$ and $d f_{\text {within }}=728$. The $R^{2}$ is an effect size calculated as the proportion of total variance in mean rankings accounted for by country. Cohen (1988) defines $R^{2}$ as small if it is .01, medium if it is .06 , and large if it is .14 or greater.

${ }^{a}$ Rival characteristics are shown in the order in which participants responded to them.

${ }^{b}$ Means that do not share a subscript are significantly different at $p \leq .05$ by post hoc comparisons, with Bonferroni correction for alpha inflation.

$* p \leq .05 . * * p \leq .01{ }^{* * *} p \leq .001$. 
cultural differences in distress about rivals emerged, as shown in Table 4. The largest cultural difference centered on the sexual skill of the rival. The Dutch sample expressed significantly more distress than did either the American or Korean sample about rivals who were more sexually skilled. Furthermore, Americans, although not reporting as much distress as the Dutch, did express significantly more distress than did Koreans about rivals who were more sexually skilled.

A second substantial cultural difference centered on the cluster of rival qualities involving status and prestige, financial prospects, and job prospects. The Korean sample exceeded both the Dutch and American samples in distress about rivals who exceeded them on this resource cluster. Americans did not differ from the Dutch in distress about the rival qualities of status and prestige or job prospects, but Americans did express greater distress than did the Dutch about rivals who had better financial prospects. This difference, however, paled in comparison to the great concern the Korean sample expressed for all three resource qualities of rivals.

A final apparent cultural difference centers on sense of humor. The Dutch reported more distress than did either the Americans or the Koreans about rivals who have a better sense of humor, whereas the Americans exceeded the Koreans on distress about this rival quality.

The remaining cultural differences are small in magnitude. Moreover, all these cultural differences must be interpreted with caution. Vagaries of translations, where even seemingly exact equivalents can carry different connotations, can affect the rankings. Furthermore, although samples from all three cultures were drawn from university populations, a lower percentage of Koreans attend university, and hence the Korean sample may represent a more elite and less representative group than is the case with the American or Dutch samples. For these reasons, the cultural differences reported here must be interpreted cau- tiously, pending deeper and more extensive studies.

\section{Discussion}

Five of the six predictions received support across the Korean, Dutch, and American samples. Men in all three cultures showed greater distress than did women in all three cultures about rivals who had better financial prospects, better future job prospects, and greater physical strength. Women in all three cultures showed greater distress than did men in all three cultures about rivals who had a more attractive face and a more attractive body. These results provide strong support for the evolutionary psychological hypothesis that men and women will be more distressed about threats from rivals who surpass them on the relevant sexlinked components of mate value or desirability (see also Dijkstra \& Buunk, 1998). These results suggest domain-specific design features, attendant not to rivals in general, but rather to specific rivals who pose a graver adaptive problem by exceeding a participant's value on sex-linked components of mate value.

One of the predictions-that men will show greater distress than will women when a rival has greater status and prestige-failed to be supported in either the Korean or American samples, although it was supported in the Dutch sample. In the context of the overall success of this evolutionary model in predicting responses to rivals, how can this relative predictive failure be accounted for? One possibility is that the prediction is simply wrong. Contrary to the evolutionary psychological model proposed here, perhaps men have not evolved a specific psychological sensitivity to rivals who are higher in status and prestige, as markers of economic. resources.

Another possibility is that "status and prestige" are terms too general to index the hypothesized sex-linked correlate of economic resources. There is independent evidence that the qualities that lead to elevated status differ in the sexes (see Buss, 
1995). Physical attractiveness, for example, leads to elevated status for both sexes, but more so for women than for men. Conversely, indicators of economic provisioning lead to elevated status for both sexes, but more so for men than for women. If attractiveness leads to high status more in women, and indicators of economic provisioning lead to high status more in men, then what constitutes a rival's "status" may differ for the sexes in ways that are obscured by the present study. Thus, the terms "status and prestige" may be too domaingeneral to provide an adequate test of the prediction. Which of these two possible explanations is correct must await research that attempts to disentangle the sex-linked meanings of status and prestige.

Future research could profitably explore the potential proximate mechanisms underlying or preceding the emotional reactions people have to potential rivals. The current findings, for example, are compatible with Tesser's (1988) self-evaluation maintenance model, as applied to the domain of jealousy: "Note that jealousy and envy were expected to be domain-specific . . . expected to be felt most strongly in the domain rated as most relevant to selfevaluation .... and in the domain where self-evaluation is most threatened" (Salovey \& Rothman, 1991, p. 275). Thus, selfevaluation processes, including comparisons between self and rival on self-relevant attributes, may be central cognitive procedures that precede the emotional reactions to rivals.

Although the current research has focused heavily on testing the theoretically derived predictions about sex differences, future research could explore both cultural differences and individual differences within a culture. For example, in cultures where men hunt to secure economic resources, the self-evaluative and rival comparison processes outlined by Salovey and Rothman might occur for hunting skills. Variations from culture to culture in the strength of emphasis on different qualities in a mate could explain cultural variations in the emotional reactions to rivals who possess differing qualities. Within cultures, some mates value intelligence and openness to new experience, whereas others value religiosity and family values. Emotional reactions to rivals may track these individual differences, so that someone mated to a partner who values intelligence might be more threatened by a rival who has just won the MacArthur "genius" award, whereas someone mated to a partner who values religiosity might be more threatened by a rival who is more devout, reverent, or pious.

Same-sex rivals pose an adaptive threat to ongoing mating relationships. A current mate might be tempted to defect from an existing relationship to mate with a rival, either temporarily through an affair or more permanently through a long-term re-mating. The more desirable the rival, in principle, the greater the temptation by a mate to defect. This study provides strong support for the hypothesis that men and women differ in the qualities of rivals most perceived as threatening and distressing. Five predictions based on this hypothesis were supported in three distinct cultures that differ widely from each other. Men in all three cultures report greater distress about rivals who are stronger, more financially viable, and who have more promising career prospects. Women in all three cultures report greater distress about rivals whose faces and bodies are more beautiful to behold. These sex differences must be interpreted within the context of a large overall similarity between the sexes; both sexes, for example, report that they would be greatly distressed by a rival who showed more kindness and understanding than they possess.

Finally, within the limitations noted, the current study adds to a growing body of evidence that supports the general hypothesis that humans have evolved psychological mechanisms in response to adaptive threats inflicted by intrasexual rivals, and the more specific hypothesis that these mechanisms are particularly sensitive to sex-linked components of mate value. 


\section{References}

Buss, D. M. (1988). The evolution of human intrasexual competition: Tactics of mate attraction. Journal of Personality and Social Psychology, 54, 616-628.

Buss, D. M. (1989). Sex differences in human mate preferences: Evolutionary hypotheses tested in 37 cultures. Behavioral and Brain Sciences, 12, 1-49.

Buss, D. M. (1994). The evolution of desire. New York: Basic Books.

Buss, D. M. (1995). Evolutionary psychology: A new paradigm for psychological science. Psychological Inquiry, 6, 1-49.

Buss, D. M. (2000). The dangerous passion: Why jealousy is as necessary as love and sex. NY: Free Press.

Buss, D. M., \& Schmitt, D. P. (1993). Sexual strategies theory: An evolutionary perspective on human mating. Psychological Review, 100, 204-232.

Buss, D. M., \& Shackelford, T. K. (1997). From vigilance to violence: Mate retention tactics in married couples. Journal of Personality and Social Psychol. ogy, 72, 346-361.

Cohen, J. (1988). Statistical power analysis for the behavioral sciences (2nd ed.). Hillsdale, NJ: Erlbaum.

Cosmides, L. (1989). The logic of social exchange: Has natural selection shaped how humans reason? Cognition, 31, 187-276.

DeKay, W. T., \& Buss, D. M. (1992). Human nature, individual differences, and the importance of context: Perspectives from evolutionary psychology. Current Directions in Psychological Science, 1, 184189.

Dijkstra, P., \& Buunk, B.P. (1998). Jealousy as a function of rival characteristics: An evolutionary perspective. Personality and Social Psychology Bulletin, 24, 1158-1166.

Ellis, B.J. (1992). The evolution of sexual attraction: Evaluative mechanisms in women. In J. Barkow, L.Cosmides, \& J. Tooby (Eds.), The adapted mind (pp. 267-288). New York: Oxford University Press.

Feingold, A. (1992). Gender differences in mate selection preferences: A test of the parental investment model. Psychological Bulletin, 112, 125-139.

Gangestad, S. W. (1993). Sexual selection and physical attractiveness: Implications for mating dynamics. Human Nature, 4, 205-235.

Graziano, W. G., Jensen-Campbell, L. A., Shebilske, L. J., \& Lundgren, S. R. (1993). Social influence, sex differences, and judgments of beauty: Putting the "interpersonal" back in interpersonal attraction. Journal of Personality and Social Psychology, $65,522-531$.

Kenrick, D. T., \& Keefe, R. C. (1992). Age preferences in mates reflect sex differences in reproductive strategies. Behavioral and Brain Sciences, 15, 1-29.
Kenrick, D. T., Neuberg, S. L., Zierk, K. L., \& Krones, J. M. (1994). Evolution and social cognition: Contrast effects as a function of sex, dominance, and physical attractiveness. Personality and Social Psychology Bulletin, 20, 210-217.

Markus, H. R., \& Kitayama, S. (1991). Culture and the self: Implications for cognition, emotion, and motivation. Psychological Review, 98, 224-253.

Salovey, P., \& Rothman, A.J. (1991). Envy and jealousy: Self and society. In P. Salovey (Ed.), The psychology of jealousy and envy (pp. 271-286). New York: Guilford Press.

Schmitt, D. P., \& Buss, D. M. (1996). Strategic self-promotion and competitor derogation: Sex and context effects on the perceived effectiveness of mate attraction tactics. Journal of Personality and Social Psychology, 70, 1185-1204.

Simpson, J. A., \& Gangestad, S. W. (1992). Sociosexuality and romantic partner choice. Journal of Personality, 60, 31-51.

Singh, D. (1993). Adaptive significance of female physical attractiveness: Role of waist-to-hip ratio. Journal of Personality and Social Psychology, 65, 293-307.

Symons, D. (1979). The evolution of human sexuality. New York: Oxford University Press.

Symons, D. (1987). If we're all Darwinians, what's the fuss about? In C. Crawford, D. Krebs, \& M. Smith (Eds.), Sociobiology and psychology (pp. 121-146). Hillsdale, NJ: Erlbaum.

Tesser, A. (1988). Toward a self-evaluation maintenance model of social behavior. In L. Berkowitz (Ed.), Advances in experimental social psychology (Vol. 21, pp. 181-227). New York: Academic Press.

Thornhill, R., \& Gangestad, S. W. (1993). Human facial beauty: Averageness, symmetry, and parasite resistance. Human Nature, 4, 237-269.

Tooke, W., \& Camire, L. (1991). Patterns of deception in intersexual and intrasexual mating strategies. Ethology and Sociobiology, 12, 345-364.

Townsend, J. M. (1987). Sex differences in sexuality among medical students: Effects of increasing socioeconomic status. Archives of Sexual Behavior, 16, 427-446.

Townsend, J. M. (1995). Sex without involvement: An evolutionary interpretation of sex differences. $A r$ chives of Sexual Behavior, 24, 171-204.

Triandis, H. C. (1995). Individualism and collectivism. Boulder, CO: Westview Press.

Wiederman, M. W., \& Allgeier, E. R. (1992). Gender differences in mate selection criteria: Sociobiological or socioeconomic explanation? Ethology and Sociobiology, 13, 115-124. 